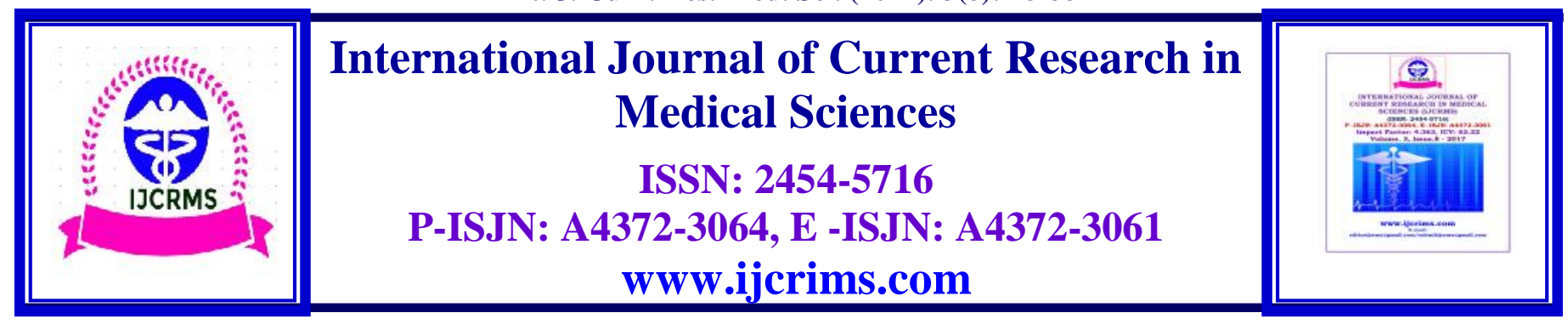

\title{
Serum lipid levels in diabetes mellitus patients with and without diabetic retinopathy: A prospective study
}

\author{
Swati Prajapati, Rashmi Kujur, U. S. Tiwari, K. P. Ranjan* \\ Department of Ophthalmology and Microbiology* \\ Gajra Raja Medical College, Gwalior, India \\ Corresponding author: Dr. K. P. Ranjan \\ Department of Microbiology, Gajra Raja Medical College, Gwalior, India \\ E-mail:drkpranjan@gmail.com
}

\begin{abstract}
Diabetes Mellitus is a group of metabolic disorder characterized by chronic hyperglycaemia. Blinding diabetic eye disease is now one of the fourth major causes of blindness in the world. Diabetic retinopathy (DR) is a major microvascular complication of diabetes. A prospective study was conducted involving 200 patients of diabetic retinopathy. The patients were divided in two groups i.e. study and control group. The relation with age wise distribution to severity of diabetic retinopathy in patients was maximum in the age group of 51-60 years. We found positive correlation of serum lipids level with development and severity of diabetic retinopathy. Thus hypolipidemic drugs can be used in diabetic retinopathy with dyslipidemia to retard its progression. Longer duration of diabetes and poor glycemic control led to worsening of retinopathy. The need for a simple, inexpensive, repeatable, and fairly reliable screening test is the need for the present time for the timely detection of diabetic retinopathy and prevent visual loss. The present study demonstrated statistically significant difference of higher serum lipid levels in diabetic retinopathy patients than non diabetic retinopathy patients. Higher Total cholesterol, Triglyceride and LDL levels are associated with more severe retinopathy and increased duration is associated with increased prevalence and more severe diabetic retinopathy. This effective monitoring of lipid profile and glycemic control would be beneficial in these patients.
\end{abstract}

Keywords: Diabetes Mellitus, diabetic retinopathy, eye disease, blindness, chronic hyperglycaemia

\section{Introduction}

Diabetes Mellitus is a heterogeneous group of metabolic disorder characterized by chronic hyperglycaemia with disturbance of carbohydrate, fat, and protein metabolism resulting from defect in insulin secretion, insulin action or both. ${ }^{[1]}$ Blinding diabetic eye disease is now one of the fourth major causes of blindness in the world after cataract, glaucoma, and trachoma. ${ }^{[2]}$ Diabetic retinopathy (DR) is a major microvascular complication of diabetes accounting for its leading cause of irreversible blindness worldwide. Assessing the risk factors of diabetic retinopathy, particularly modified risk factors, is important for early intervention to reduce the onset and 
progression of diabetic retinopathy. Several population-based epidemiological studies have investigated the risk factors of diabetic retinopathy. ${ }^{[3]}$ These studies consistently established that a longer diabetic duration, hyperglycaemia and hypertension were associated with increased risk of diabetic retinopathy. High serum lipid levels have also been proposed as a risk factor for diabetic retinopathy. High lipid levels are known to cause endothelial dysfunction due to a reduced bioavailability of nitric oxide and this endothelial dysfunction was suggested to play a role in retinal exudates formation in diabetic retinopathy ${ }^{[4]}$.

Proliferative diabetic retinopathy (PDR) consists of newly formed vessels or fibrotic tissue arising from retina or optic disc. When they arise at or within disc diameter of optic disc, they are referred to as neovascularizaton of disc (NVD). When they arise further than one disc diameter away, they are called neovascularizaton elsewhere (NVE). Maculopathy is the most common cause of visual impairment in diabetic patients. Various studies have shown a positive correlation between elevated serum lipids (TG, LDL, TC) and macro vascular complications like ischemic heart disease. $^{[5]}$

However, studies of association of elevated serum lipids with microvascular complications like diabetic retinopathy have shown varying results. Various epidemiological risk factors have been identified for the development and progression of diabetic retinopathy. The best predictor of diabetic retinopathy is the duration of disease. ${ }^{[5]}$ In this study an attempt was made to quantify and specify the role of various components of serum lipids with the prevalence of diabetic retinopathy. We also found the distribution of cases according to age and sex, estimation of fasting blood, relation of duration of diabetes and diabetic retinopathy, estimation of serum lipids level with severity of diabetic retinopathy and role of different serum lipids level in severity of diabetic retinopathy.

\section{Materials and Methods}

A prospective study was conducted in the Department of Ophthalmology and Central Pathology Laboratory of Gajra Raja Medical College, Gwalior from February 2015 to August 2016. A total of 200 patients who attended outpatient department of ophthalmology with the case of type I and II diabetes mellitus were included in this study. The patients were divided in two groups. Each group consisted of 100 patients with diabetic retinopathy (study group) and without diabetic retinopathy (control group) respectively.

Patients included in this study had been diagnosed to have diabetes mellitus as per criteria of American Diabetes association has laid down criteria ${ }^{[6]}$

Inclusion criteria was patients of diabetes mellitus type I and II with and without retinopathy and who were willing to sign an informed consent as per requirements of the study.

Exclusion criteria was those in which dilatation of pupils is contraindicated such as angle closure glaucoma, patients with hazy media which impairs visualization of the fundus, patients on hypolipidemic agent and pregnancy and retinitis pigmentosa. Fundus examination and indirect ophthalmoscopy were done after mydriasis of pupil as per standard guidelines.

All cases of diabetic retinopathy were graded into following classes on the basis of ETDRS classification.

1. Non Proliferative Diabetic Retinopathy(NPDR): Mild NPDR, Moderate NPDR, Severe NPDR and Very Severe NPDR

2. Proliferative Diabetic Retinopathy (PDR): Mild to Moderate and High risk PDR

3. Diabetic Macular Edema

4. Advance Diabetic Eye Disease 
Laboratory Procedure: Five $\mathrm{ml}$ of fasting blood sample was collected under asepsis from anterior cubital vein using disposable syringes to asses fasting blood sugar and lipid profile. The fasting blood sugar level and fasting serum lipid profile were carried out by enzymatic method using auto analyzer. Dyslipidemia was defined by the presence of one or more than one abnormal serum lipid concentrations. ${ }^{[7]}$

Statistical Analysis: The statistical analysis was performed using standard tests. SPSS 20.0 software was used for statistical analysis of biochemical parameters for the subjects were analyzed by using unpaired students" test and $\mathrm{p}<0.05$ was accepted as statistically significant.

\section{Results/Observations}

A total of 200 patients were included in this study. The patients were divided in two groups. Each group consisted of 100 patients with diabetic retinopathy (study group) and without diabetic retinopathy (control group) respectively. There were 53 males and 47 females respectively in study group whereas 56 males and 44 females in control group. The relation with age wise distribution to severity of diabetic retinopathy in patients was maximum in the age group of 51-60 years and followed by 41-50, 61-70, 31-40, 71-80 and 20-30 respectively. The mean age of patients was 56.42 \pm 9.26 and in the control group $53.89 \pm 12.78$. The distribution of study cases according to severity of diabetic retinopathy was found as 42, 25, 11 and 16 in Mild NPDR, Moderate NPDR, Very severe NPDR and PDR respectively whereas the distribution of study cases according to severity of diabetic retinopathy was found in 42, 25, 11 and 16 in Mild NPDR respectively. The duration of diabetes in various grades of diabetic retinopathy was found in the study group, Mild NPDR was seen in 42, moderate in 25 severe, very severe 11 and PDR was seen in 16 respectively. The average duration of diabetes in the control group was $6.58 \pm 6.59$ and in cases $15.08 \pm 8.01$. The mean duration of DM among of all patients with NPDR was 12.86 \pm 6.41 .Among subject those with very severe NPDR and PDR had the longest duration of diabetes, the mean duration being $23.3 \pm 4.82$ and $26.69 \pm 5.02$ per year followed by those with severe, moderate and mild NPDR respectively. The mean duration being $14.5 \pm 3.39,12.48 \pm 5.32$, $10.1 \pm 4.7$ years respectively.[Table 1]

Table 1: Duration of diabetes in various grades of diabetic retinopathy

\begin{tabular}{|l|c|c|}
\hline \multicolumn{1}{|c|}{ Group } & Duration $($ mean \pm stdv) years & P value \\
\hline Control vs study & $6.58 \pm 6.59 / 15.08 \pm 8.01$ & 0.0001 \\
\hline NPDR vs PDR & $12.86 \pm 6.41 / 26.69 \pm 5.02$ & 0.0001 \\
\hline Mild NPDR vs moderate NPDR & $10.1 \pm 4.7 / 12.48 \pm 5.32$ & 0.064 \\
\hline Moderate vs severe NPDR & $12.48 \pm 5.32 / 14.5 \pm 3.39$ & 0.3852 \\
\hline Severe vs very severe NPDR & $14.5 \pm 3.39 / 23.3 \pm 4.82$ & 0.0013 \\
\hline Very severe NPDR vs PDR & $23.3 \pm 4.82 / 26.69 \pm 5.02$ & 0.0921 \\
\hline Mild vs severe NPDR & $10.1 \pm 4.7 / 23.3 \pm 4.82$ & 0.0001 \\
\hline
\end{tabular}

In this study the average duration of diabetes was compared among the patients in both groups. The average duration of diabetes in two groups was $6.58 \pm 6.59$ (control) and 15.08 \pm 8.01 (subject) years. This difference was found to be statistically significant $(\mathrm{p}<0.0001)$ and also compared the mean duration of diabetes mellitus among subgroups of NPDR and PDR. Mean fasting blood sugar in patients with PDR was maximum $(395.2 \pm 66.29 \mathrm{mg} / \mathrm{dl})$ followed by very severe NPDR (319.18 $\pm 27.34 \mathrm{mg} / \mathrm{dl})$, severe NPDR $(241.83 \pm 85.91 \mathrm{mg} / \mathrm{dl})$, moderate NPDR $(209.12 \pm 82.79 \mathrm{mg} / \mathrm{dl})$, and Mild NPDR $(142.7 \pm 32.7 \mathrm{mg} / \mathrm{dl})$ respectively. [Table 2] 
Int. J. Curr. Res. Med. Sci. (2017). 3(8): 78-88

Table 2: Fasting blood sugar and severity of diabetic retinopathy

\begin{tabular}{|l|c|c|}
\hline \multicolumn{1}{|c|}{ Group } & Number & FBS Mean \pm STDV(mg/dl) \\
\hline Control & 100 & $182.03 \pm 30.9$ \\
\hline Mild NPDR & 42 & $142.7 \pm 32.7$ \\
\hline Moderate NPDR & 25 & $209.12 \pm 82.79$ \\
\hline Severe NPDR & 6 & $241.83 \pm 85.91$ \\
\hline Very severe NPDR & 11 & $319.18 \pm 27.34$ \\
\hline PDR & 16 & $395.2 \pm 66.29$ \\
\hline
\end{tabular}

Fasting blood sugar and severity of diabetic retinopathy in all groups such as Control vs Study, NPDR vs PDR, Mild NPDR vs moderate
NPDR, Moderate vs severe NPDR, Severe vs very severe NPDR, Very severe NPDR vs PDR and Mild vs severe NPDR is shown in table 3.

Table 3: Fasting blood sugar and severity of diabetic retinopathy

\begin{tabular}{|l|c|c|}
\hline \multicolumn{1}{|c|}{ Group } & Fbs $(\mathbf{m g} / \mathbf{d l})$ mean \pm stdv & P value \\
\hline Control vs Study & $182.03 \pm 39.05 / 225.08 \pm 108$ & 0.003 \\
\hline NPDR vs PDR & $192.66 \pm 81.77 / 395.2 \pm 66.29$ & 0.0001 \\
\hline Mild NPDR vs moderate NPDR & $142.7 \pm 32.7 / 209.12 \pm 82.79$ & 0.0001 \\
\hline Moderate vs severe NPDR & $209.12 \pm 82.79 / 241.83 \pm 85.91$ & 0.3942 \\
\hline Severe vs very severe NPDR & $241.83 \pm 85.91 / 319.18 \pm 27.34$ & 0.0127 \\
\hline Very severe NPDR vs PDR & $319.18 \pm 27.34 / 395.2 \pm 66.29$ & 0.0014 \\
\hline Mild vs severe NPDR & $142.7 \pm 32.7 / 241.83 \pm 85.91$ & 0.0001 \\
\hline
\end{tabular}

The average total cholesterol level in the control group was $179.77 \pm 50.86 \mathrm{mg} / \mathrm{dl}$ and the average TC in study group was $263.45 \pm 64.7 \mathrm{mg} / \mathrm{dl}$. Among cases the mean cholesterol levels in mild NPDR, moderate NPDR, severe NPDR, very severe NPDR, and PDR were 206.64 \pm 14.76 $\mathrm{mg} / \mathrm{dl}, 249.12 \pm 11.02 \mathrm{mg} / \mathrm{dl}, 305.5 \pm 20.09 \mathrm{mg} / \mathrm{dl}$, $327.54 \pm 19.0 \mathrm{mg} / \mathrm{dl}$, and $375.12 \pm 9.98 \mathrm{mg} / \mathrm{dl}$ respectively. Thus, the mean TC levels showed statistically significant correlation indicating that elevated TC levels were associated with an increasing severity of retinopathy [Table.4 and 5]

Table 4: Total cholesterol and severity of diabetic retinopathy

\begin{tabular}{|l|c|c|}
\hline \multicolumn{1}{|c|}{ Group } & Number & Total cholesterol (mean \pm sd)mg/dl \\
\hline Control & 100 & $179.77 \pm 50.86$ \\
\hline Mild NPDR & 42 & $206.64 \pm 14.76$ \\
\hline Moderate NPDR & 25 & $249.12 \pm 11.02$ \\
\hline Severe NPDR & 6 & $305.5 \pm 20.09$ \\
\hline Very severe NPDR & 11 & $327.54 \pm 19.0$ \\
\hline PDR & 16 & $375.12 \pm 9.98$ \\
\hline
\end{tabular}


Int. J. Curr. Res. Med. Sci. (2017). 3(8): 78-88

Table 5: Total cholesterol and severity of diabetic retinopathy

\begin{tabular}{|l|c|c|}
\hline \multicolumn{1}{|c|}{ Group } & Total cholesterol $($ mean \pm stdv)mg/dl & P value \\
\hline Control vs Study & $179.77 \pm 50.86 / 263.45 \pm 64.7$ & 0.0002 \\
\hline NPDR vs PDR & $242.17 \pm 46.04 / 375.12 \pm 9.98$ & 0.0001 \\
\hline $\begin{array}{l}\text { Mild NPDR vs moderate } \\
\text { NPDR }\end{array}$ & $206.64 \pm 14.76 / 249.12 \pm 11.02$ & 0.0001 \\
\hline Moderate vs severe NPDR & $249.12 \pm 11.02 / 305.5 \pm 20.09$ & 0.0001 \\
\hline Severe vs very severe NPDR & $305.5 \pm 20.09 / 327.54 \pm 19.0$ & 0.0405 \\
\hline Very severe NPDR vs PDR & $327.54 \pm 19.0 / 375.12 \pm 9.98$ & 0.0001 \\
\hline Mild vs severe NPDR & $206.64 \pm 14.76 / 305.5 \pm 20.09$ & 0.0001 \\
\hline
\end{tabular}

The mean serum triglyceride in our study group was $178.58 \pm 47 \mathrm{mg} / \mathrm{dl}$ which was significantly higher than the mean level of $153.08 \pm 84.52 \mathrm{mg} / \mathrm{dl}$ in the control group. The mean TG levels in mild
NPDR, moderate NPDR, severe NPDR, very severe NPDR and PDR were 154.08 \pm 84.52 , $176.96 \pm 33.89, \quad 226.5 \pm 146.6, \quad 189 \pm 3.53$, $218.25 \pm 17.14$ respectively [Table. 6 and 7 ]

Table 6: Triglyceride and severity of diabetic retinopathy

\begin{tabular}{|l|c|c|}
\hline \multicolumn{1}{|c|}{ Group } & Number & Triglyceride $($ mean \pm stdv)mg/dl \\
\hline Control & 100 & $153.08 \pm 84.52$ \\
\hline Mild NPDR & 42 & $154.85 \pm 11.52$ \\
\hline Moderate NPDR & 25 & $176.96 \pm 33.89$ \\
\hline Severe NPDR & 6 & $226.5 \pm 146.6$ \\
\hline Very severe NPDR & 11 & $189 \pm 31.53$ \\
\hline PDR & 16 & $218.25 \pm 17.14$ \\
\hline
\end{tabular}

Table 7: Triglyceride and severity of diabetic retinopathy

\begin{tabular}{|l|c|c|}
\hline \multicolumn{1}{|c|}{ Group } & Triglyceride $($ mean \pm stdv)mg/dl & P value \\
\hline Control vs Study & $153.08 \pm 84.52 / 178.58 \pm 47$ & 0.0101 \\
\hline NPDR vs PDR & $171.02 \pm 47.12 / 218.25 \pm 17.14$ & 0.0002 \\
\hline Mild NPDR vs moderate NPDR & $154.85 \pm 11.52 / 176.96 \pm 33.89$ & 0.0002 \\
\hline Moderate vs severe NPDR & $176.96 \pm 33.89 / 226.5 \pm 146.6$ & 0.1148 \\
\hline Severe vs very severe NPDR & $226.5 \pm 146.6 / 189 \pm 31.53$ & 0.4205 \\
\hline Very severe NPDR vs PDR & $189 \pm 31.53 / 218.25 \pm 17.14$ & 0.0044 \\
\hline Mild vs severe NPDR & $154.85 \pm 11.52 / 226.5 \pm 146.6$ & 0.0017 \\
\hline
\end{tabular}

The mean serum levels of HDL in the study and control groups, the level being $40.34 \pm 2.2 \mathrm{mg} / \mathrm{dl}$ and $47.2 \pm 9.02 \mathrm{mg} / \mathrm{dl}$ respectively. This difference was found to be statistically significant. The mean
HDL levels in mild NPDR, moderate NPDR, severe NPDR, very severe NPDR and PDR was $40.64 \pm 2.64,40.6 \pm 1.87,40.17 \pm 2.04$, $39.73 \pm 1.68$ ,39.63 $\pm 1.71 \mathrm{in} \mathrm{mg} / \mathrm{dl}$ respectively [Table 8 and 9] 
Int. J. Curr. Res. Med. Sci. (2017). 3(8): 78-88

Table 8: HDL and severity of diabetic retinopathy

\begin{tabular}{|l|c|c|}
\hline Group & Number & HDL (mean \pm stdv) mg/dl \\
\hline Control & 100 & $47.2 \pm 9.02$ \\
\hline Mild NPDR & 42 & $40.64 \pm 2.64$ \\
\hline Moderate NPDR & 25 & $40.6 \pm 1.87$ \\
\hline Severe NPDR & 6 & $40.17 \pm 2.04$ \\
\hline Very severe NPDR & 11 & $39.73 \pm 1.68$ \\
\hline PDR & 16 & $39.63 \pm 1.71$ \\
\hline
\end{tabular}

Table: 9 HDL and severity of diabetic retinopathy

\begin{tabular}{|l|c|c|}
\multicolumn{1}{|c|}{ Group } & Hdl mg/dl mean \pm stdv & P value \\
\hline Control vs Study & $47.2 \pm 9.02 / 40.34 \pm 2.2$ & 0.0001 \\
\hline NPDR vs PDR & $40.47 \pm 2.89 / 39.63 \pm 1.71$ & 0.2642 \\
\hline Mild NPDR vs moderate NPDR & $40.64 \pm 2.64 / 40.6 \pm 1.87$ & 0.9423 \\
\hline Moderate vs severe NPDR & $40.6 \pm 1.87 / 40.17 \pm 2.04$ & 0.6224 \\
\hline Severe vs very severe NPDR & $40.17 \pm 2.04 / 39.73 \pm 1.68$ & 0.6385 \\
\hline Very severe NPDR vs PDR & $39.73 \pm 1.68 / 39.63 \pm 1.71$ & 0.8817 \\
\hline Mild vs severe NPDR & $40.64 \pm 2.64 / 40.17 \pm 2.04$ & 0.6785 \\
\hline
\end{tabular}

The mean serum LDL levels in the study group and control group, which were $144.9 \pm 38.15 \mathrm{mg} / \mathrm{dl}$ and $108.43 \pm 34.62 \mathrm{mg} / \mathrm{dl}$ respectively. The difference was statistically significant. The mean LDL levels in mild NPDR, moderate NPDR ,severe NPDR, very severe NPDR and PDR were $126.3 \pm 23.2, \quad 128.04 \pm 24.27, \quad 164.83 \pm 46.91$, $168.18 \pm 21.86,194.0 \pm 39.65$ respectively [Table 10 and 11]

Table 10LDL and severity of diabetic retinopathy

\begin{tabular}{|l|c|c|}
\hline \multicolumn{1}{|c|}{ Group } & Number & Mean \pm SD \\
\hline Control & 100 & $108.43 \pm 34.62$ \\
\hline Mild NPDR & 42 & $126.3 \pm 23.2$ \\
\hline Moderate NPDR & 25 & $128.04 \pm 24.27$ \\
\hline Severe NPDR & 6 & $164.83 \pm 46.91$ \\
\hline Very severe NPDR & 11 & $168.18 \pm 21.86$ \\
\hline PDR & 16 & $194 . \pm 39.65$ \\
\hline
\end{tabular}

Table 11 LDL and severity of diabetic retinopathy

\begin{tabular}{|l|c|c|}
\hline \multicolumn{1}{|c|}{ Group } & LDL(mean \pm stdv)mg/dl & P value \\
\hline Control vs study & $108.43 \pm 34.62 / 144.49 \pm 38.15$ & 0.0001 \\
\hline NPDR vs PDR & $135.05 \pm 29.83 / 194 . \pm 39.65$ & 0.0001 \\
\hline Mild NPDR vs moderate NPDR & $126.3 \pm 23.2 / 128.04 \pm 24.27$ & 0.7391 \\
\hline Moderate vs severe NPDR & $128.04 \pm 24.27 / 164.83 \pm 46.91$ & 0.0118 \\
\hline Severe vs very severe NPDR & $164.83 \pm 46.91 / 168.18 \pm 21.86$ & 0.8111 \\
\hline Very severe NPDR vs PDR & $168.18 \pm 21.86 / 194 . \pm 39.65$ & 0.0552 \\
\hline Mild vs severe NPDR & $126.3 \pm 23.2 / 164.83 \pm 46.91$ & 0.0017 \\
\hline
\end{tabular}




\section{Discussion}

This study included 200 patients of diabetes mellitus which were divided in two groups- One group consisted of 100 patients without DR (Control); another group of 100 patients with DR (Study).These patients underwent a detailed anterior segment and fundus examination under full mydriasis. Fasting blood samples were collected to analyze fasting blood sugar and serum lipids levels. There was statistically no difference as far as the age and sex of the patients were concerned in the study and control group.

In the present study average duration of diabetes in the control and study group was $6.59 \pm 6.59$ and $15.08 \pm 8$.1years respectively and difference was statistically significant. The mean value of duration of diabetes in mild NPDR, moderate NPDR, severe NPDR, very severe NPDR and PDR was $10.1 \pm 4.7,12.48 \pm 5.32,14.5 \pm 3.39$, $23.3 \pm 4.82,26.69 \pm 5.02$ respectively. Hence increased duration of diabetes was found to be associated with increased development of diabetic retinopathy. Our study results were consistent with the results of other authors; West et al, Klein et al, Palmberg et al. ${ }^{[8-10]}$ WESDR Study and Liverpool Diabetic eye study observed that the most important risk factor of development of diabetic retinopathy was the duration of disease. Klein et al reported that incidence of diabetic retinopathy was $74 \%$, the rate of progression of retinopathy $64 \%$, and progression to proliferative retinopathy $17 \%$.respectively. ${ }^{[11]}$ Mohan et al, in their study found that as the duration of diabetes increased, the prevalence of diabetic retinopathy also increased. ${ }^{[12]}$ The association of longer duration with higher risk of DR was in accordance with previously published reports in DCCT; UKPDS; Larsson et al. ${ }^{[13]}$ It is obvious that patients with retinopathy significantly had a longer mean duration of diabetes. Many other studies in India also have found an increased prevalence of diabetic retinopathy as duration of diabetes increased. ${ }^{[14,15]}$

In the present study average fasting blood sugar in the control and study group was $182.03 \pm 39.05$ and $225.08 \pm 108 \mathrm{mg} / \mathrm{dl}$ respectively and difference was statistically significant. The mean FBS levels in mild NPDR, moderate NPDR, severe NPDR, very severe NPDR and PDR were 142.7 \pm 32.7 , $209.12 \pm 82.79, \quad 241.83 \pm 85.91, \quad 319.18 \pm 27.34$, $395.2 \pm 66.29 \mathrm{mg} / \mathrm{dl}$ respectively. It was observed that the mean values in all groups were above normal limits and mean blood sugar levels were more with increasing severity of retinopathy, there was statistically significant correlation between different groups noted in our study reinforcing the fact that the development and progression of Diabetic Retinopathy is influenced by the level of hyperglycemia. Our study findings are consistent with Cetin et al ,who found significant correlation between raised FBS and severity of diabetic retinopathy. ${ }^{[16]}$ Rianita et al found that long term glycemic control plays an important role in delaying the onset and slowing down the progression of Diabetic retinopathy. ${ }^{[17]}$ DCCT Cohort study in 1995 also showed that raised FBS was associated with increased incidence and severity of diabetic retinopathy. Shrivastav $M$ et al also found significant association of occurrence and severity of diabetic retinopathy with raised $\mathrm{FBS} .{ }^{[18]}$

The association between serum lipid levels and diabetic retinopathy has been investigated in many studies. ${ }^{[2,5,13,18,19,20,21]}$ The average total cholesterol (TC) levels in our study group was $263.45 \pm 65.7 \mathrm{mg} / \mathrm{dl}$ which was significantly higher than that in the control group and this is similar to studies reported by Dhir et al and Chew et al. ${ }^{[2,}$ ${ }^{22]}$ The mean cholesterol levels in mild NPDR, moderate NPDR, severe NPDR, very severe NPDR and PDR were 206.64 \pm 14.76 , $249.12 \pm 11.02, \quad 305.5 \pm 20.09, \quad 327.54 \pm 19.0$, and $375.12 \pm 9.98 \mathrm{mg} / \mathrm{dl}$ respectively. Thus the mean TC levels showed statistically significant correlation indicating that elevated TC levels were associated with an increasing severity of retinopathy. ETDRS showed that TC levels in diabetic retinopathy patient's were twice with normal levels. Larsson et al found significant relation between higher levels of serum TC and severity of diabetic retinopathy. ${ }^{[13]} \mathrm{Al}-\mathrm{Bdour}$ et al also found positive relation between diabetic retinopathy and raised TC levels. ${ }^{[20]} \mathrm{M}$. Rema et al, Shrivastava $\mathrm{M}$ et al and Klein et al also found positive relation between raised TC and diabetic retinopathy. ${ }^{[18,23,24]}$ The Hoorn study showed that 
diabetic retinopathy and hard exudates are positively related to raise TC. In CURES eye study, serum cholesterol levels were more than in subjects with moderate NPDR compared with subjects without diabetic retinopathy. ${ }^{[24]}$ They also showed an association of diabetic macular edema in type II DM subjects with raised cholesterol levels. Ucgun et al also showed a positive correlation between CSME and hypercholestermia. ${ }^{[25]}$ However in contrast to this study, several studies reported that there was no relationship between lipid levels and development and progression of diabetic retinopathy. ${ }^{[13,20,21,23 \text {, }}$ $26,27,28]$

In particular, Agardh et al found no significant difference in the levels of serum cholesterol, serum triglyceride, LDL cholesterol and HDL cholesterol in diabetic patients with proliferative diabetic retinopathy and those with no evidence of retinopathy. ${ }^{[20]}$ Klein et al studied the relationship of total cholesterol and HDL to the incidence and progression of diabetic retinopathy in patients with younger onset diabetes mellitus. ${ }^{[23]}$ Invariable associations were significant for association of retinal lesion with total cholesterol/HDL, but multivariate associations were not significant.

The average serum triglyceride (TG) in our study group was $178.58 \pm 47 \mathrm{mg} / \mathrm{dl}$ which was significantly higher than the average level of $153.08 \pm 84.52 \mathrm{mg} / \mathrm{dl}$ in the control group. The mean TG levels in mild NPDR, moderate NPDR, severe NPDR, very severe NPDR and PDR were $154.08 \pm 84.52, \quad 176.96 \pm 33.89, \quad 226.5 \pm 146.6$, $189 \pm 3.53$, and $218.25 \pm 17.14 \mathrm{mg} / \mathrm{dl}$ respectively. Hence the mean TG levels showed statistically significant correlation and showed that elevated TG levels were associated with increasing severity of diabetic retinopathy except in severe and very severe NPDR grades. Triglycerides are significant risk factor for presence of diabetic retinopathy as per EURODIAB prospective and other studies. $[21,24,25,29,30,31,32$,$] Unlike other$ studies ,the authors found no association of triglycerides and development of DR. ${ }^{[13,19,22]}$

There was statistically significant difference in the serum levels of HDL in the study and control groups, the level being $40.34 \pm 2.2 \mathrm{mg} / \mathrm{dl}$ and
47.2 $\pm 9.02 \mathrm{mg} / \mathrm{dl}$ respectively. The mean HDL levels in mild NPDR, moderate NPDR, severe NPDR, very severe NPDR and PDR was $40.64 \pm 2.64,40.6 \pm 1.87,40.17 \pm 2.04,39.73 \pm 1.68$, $39.63 \pm 1.71 \mathrm{mg} / \mathrm{dl}$ respectively and no significant correlation was found between all the groups. However other found strong inverse correlation between HDL and incidence of DR, whereas no correlation was seen between severity of DR with serum HDL. ${ }^{[30,33]}$ The DCCT investigators found that severity of retinopathy was associated with increasing level of $\mathrm{TG}$ and decreased level of HDL. Aggarwal RP et al also found similar results. ${ }^{[14]}$ Sasongko BM et al found that HDL-C level was inversely associated with DR. ${ }^{[34]}$

There was statistically significant difference in the serum LDL levels in our study group and control group, which were $144.9 \pm 38.15 \mathrm{mg} / \mathrm{dl}$ and $108.43 \pm 34.62 \mathrm{mg} / \mathrm{dl}$ respectively. The mean LDL levels in mild NPDR, moderate NPDR, severe NPDR, very severe NPDR and PDR were $126.3 \pm 23.2, \quad 128.04 \pm 24.27, \quad 164.83 \pm 46.91$, $168.18 \pm 21.86$, and $194.0 \pm 39.65 \quad \mathrm{mg} / \mathrm{dl}$ respectively. Statistically significant difference was seen between NPDR vs PDR, Mild NPDR vs Severe NPDR and Moderate vs Severe NPDR. ETDRS found that the elevated levels of LDL are independent risk factor for development of hard exudates; Agarwal et al and Sachdev et al also observed raised level of LDL in patients with diabetic retinopathy. ${ }^{[51,36]}$ Miljanovic et al, the DCCT study showed that increased level of LDL double the risk of CSME. ${ }^{[29]}$ Gupta et al found that diabetics with raised LDL levels showed higher prevalence of DR compared to others. ${ }^{[15]}$ Rasoulinejad SA et al also showed that high serum LDL-cholesterol is associated with severity of diabetic retinopathy particularly with macular edema. ${ }^{[37]}$ In contrast, Haffner et al conducted a study on 22 younger onset and 8 older onset subjects with diabetes. ${ }^{[27]}$ They could not derive a link between higher levels of serum lipids and severity of retinopathy in either younger or older onset subjects. Vinodhini V M et al also found no relation. $^{[6]}$ Verrotti et al also studied the lipid profile in patients with different grades of diabetic retinopathy and the estimated serum lipid levels were similar in all grades. ${ }^{[13]}$ 
In summary in this study we found positive correlation of serum lipids level with development and severity of diabetic retinopathy. Thus hypolipidemic drugs can be used in diabetic retinopathy with dyslipidemia to retard its progression. Longer duration of diabetes and poor glycemic control led to worsening of retinopathy. The need for a simple, inexpensive, repeatable, and fairly reliable screening test is the need for the present time for the timely detection of diabetic retinopathy and prevent visual loss.

\section{Conclusion}

The present study demonstrated statistically significant difference of higher serum lipid levels in diabetic retinopathy patients than non diabetic retinopathy patients. Higher total cholesterol, Triglyceride and LDL levels are associated with more severe retinopathy and increased duration is associated with increased prevalence and more severe diabetic retinopathy. Hence effective monitoring of lipid profile and glycemic control would be beneficial in these patients.

\section{References}

1. Peter H Bennett, Williams C. Knowler: Joslin's Diabetes mellitus, 13th edition.Definition, diagnosis and classification of diabetes mellitus and glucose homeostasis, chapter 19, 331-339.

2. Chew EY, Klein ML, Ferris FL 3rd, Remaley NA, Murphy RP, Chantry K,Hoogwerf BJ, Miller D. Association of elevated serum lipid levels with retinal hard exudate in diabetic retinopathy. Early Treatment Diabetic Retinopathy Study (ETDRS)Report 22. Arch Ophthalmol. 1996; 114(9): 1079-84.

3. Yau JW, Rogers SL, Kawasaki R, Lamoureux EL, Kowalski JW, Bek T,et al. Meta-Analysis for Eye Disease (META-EYE) Study Group.Global prevalence and major risk factors of diabetic retinopathy.Diabetes Care 2012;35:556-64.
4. Landmesser U, Hornig B, Drexler $\mathrm{H}$. Endothelial dysfunction in hypercholesterolemia: Mechanisms, pathophysiological importance, and therapeutic interventions. Semin Thromb Hemost 2000;26:529-37.

5. Klein R, Klein BEK. Epidemiology of proliferative diabetic retinopathy. Diabetes Care. 1992;15:1875-1891

6. Early Treatment of Diabetic Retinopathy Study Research Group.Grading diabetic retinopathy from stereoscopic colour fundus photographs - an extension of the modified Airlie House classification. ETDRS report number 10. Ophthalmology 1991; 98: 786-806.

7. Ram VinodMahato. Association between glycaemic control and serum lipid profile in type 2 diabetic patients: Glycated haemoglobin as a dual biomarker. Biomedical Research 2011; 22 (3): 375380.

8. Klein BEK, Klein R, Moss SE. The WESDR 3: the prevalence and risk factor of diabetic retinopathy when age at diagnosis in 30 or more years. Arch ophthalmology. 1984; 102:520-532.

9. West KM, Ahuja MMS, Bennett PH et al. interrelationship of microangiopathy, plasma glucose andother risk factor in 352 diabetic patients. A multinational study. Diabetologia. 1982; 22:412-420.

10. Palmberg P, Smith M, Walman S, the natural history of retinopathy in insulin dependent juvenile onset diabetes. Ophthalmology 1998; 88:613-618.

11. Klein BEK, Klein R, Moss SE. The WESDR 3: the prevalence and risk factor of diabetic retinopathy. Arch ophthalmology. 1994; 112:1217-1228.

12. Mohan V, Vijayprabha R, Rom M . Vascular complication in long term south Indians with NIDDM of over 25 years duration. Diabetes Res Clin Pract 1996; 31:133. 
13. Larsson LI, Alm A, Lithner F, Dahlen G, Bergstrom R: The association of hyperlipedemia with retinopathy in diabetic patients aged 15-50years in the county of Umea. Acta Ophthalmologica Scandinavica, 1999;77(5):585-591.

14. Agarwal RP, Meeta single, vyas SP, Sabir Hussain , Jain GC , Kochar DR. Prevalence of retinopathy and its relation with various risk factor in type 1 DMHospital based study India. International journal of Diabetes In Developing Countries 2001; 21:184-190.

15. Gupta A, Gupta V, Thapar S, Bhansali A. Lipidlowering drug atorvastatin as an adjunct in the management of diabetic macular edema. Am J Ophthalmol 2004. 137(4):675-682.

16. Rasoulinejad SA, Iri HO. Determination of serum lipid profile in patients with diabetic macular edema that referred to Shahid Beheshti and Ayatollah Rouhani Hospitals, Babol during 2011-2012. Caspian J Intern Med. 2015 Spring;6(2):77-81.

17. Rianita, Saptawati Bardosono, Andi Arus Victor . Relationship between plasma lipid profile and the severity of diabetic retinopathy in type 2 diabetes patients Vol.17, No 4, October - December 2008 221-226

18. Srivastava Mitali, Kumar Annapurna, Sum athi S. Association of Lipid Profile with Severity of Retinopathy in Patients with Type-2 Diabetes Mellitus journal of Research in Medical Education \& Ethics.2015;5:220-226

19. Dornan TL, Carter RD, Bron AJ, Turner RC, Mann JI: Low density Lipoprotein cholesterol: An association with severity of diabetic retinopathy. Diabetologia, 1982; 22(3):167-170.

20. Al-Bdour MD, Al-Till MI, Abu Samra KMRisk Factors for Diabetic Retinopathy among Jordanian Diabetics. Middle East Afr J Ophthalmol. 2008 Apr; 15(2): 77-79.

21. Alpana Mathur, Rishi Mathur . Study of Association of Serum Lipids with Diabetic Retinopathy in Type 2 Diabetes Mellitus
People's Journal of Scientific Research2013;5:25-28.

22. Dhir SP , Dhiya R ,Ram J . Serum lipoprotein cholesterol profilein diabetic retinopathy. Ind J Ophthalmol. 1984; 113:36-51.

23. Klein RL, Hunter SJ, JenkinsAJ,Zheng D,Semler AJ ,CLORE J, Garvey WT, Fibronogen is a markr for nephropathy and peripheral vascular disease in type 1 diabetese: studies of plasma fibrinogen and fibrinogen polymorphism in theDCCT/EDIC cohort, Diabetes Care 1999;26:1439-1448.

24. Rema M, Srivastava BK, Anitha B, Deepa $\mathrm{R}$, Mohan V. Association of serum lipids with diabetic retinopathy in urban South Indians-the Chennai Urban Rural Epidemiology Study (CURES) Eye Study2. Diabet Med 2006;23:1029-36.

25. Ucgun NI, Yildirim Z, Kiliç N, Gürsel E. The importance of serum lipids in exudative diabetic macular edema in type 2 diabetic patients. Ann N Y Acad Sci 2007. 1100:213-217.

26. Benarous R, Sasongko MB, Qureshi S, Fenwick E, Dirani M, Wong TY, et al. Differential association of serum lipids with diabetic retinopathy and diabetic macular edema. Invest Ophthalmol Vis Sci 2011;52:7464-9.

27. Haffner SM, Mitchell BD, Moss SE, Stern MP, Hazuda HP, Patterson J, et al. Is there an ethnic difference in the effect of risk factors for diabetic retinopathy? Ann epidemiol 1993;3:2-8.

28. Cetin EN,Bulgu Y, Ozdemir S, Topsakal S, Akin F, Aybek H,Yildrim C. Association of serum lipid levels with diabetic retinopathy. 2013;6(3):346-349

29. Miljanovic B, Glynn RJ, Nathan DM, Manson JE, Schaumberg DA. A prospective study of serum lipids and risk of diabetic macular edema in type 1 diabetes. Diabetes2004. 53(11):28832892. 
30. Timothy J. Lyons, Alicia J. Jenkins, Deyi Zheng, Daniel T. Lackland, Daniel McGee,W. Timothy Garvey, Richard L. Klein, and The DCCT/EDIC Research Group. Diabetic Retinopathy and Serum Lipoprotein Subclasses in the DCCT/EDIC Cohort. Invest. Ophthalmol. Vis. Sci. March 2004 ; 45 : 3910-918.

31. Weisweiler P, Schwandt P. Type 1 versus type II diabetes mellitus: Characterisation of serum lipoprotein alterations. Eur J Clin Invest 1987; 17: 87-91.

32. Hui-yan ZHANG, Jian-yong WANG, Guishuang YING, Li-ping SHEN, Zhe ZHANG Serum lipids and other risk factors for diabetic retinopathy in Chinese type 2 diabetic patients $\mathrm{J}$ Zhejiang UnivSci B (Biomed \& Biotechnol) 2013 14(5):392-399

33. Agroiya P, Philip R, Saran S, Gutch M, Tyagi R, Gupta KK. Association of serum lipids with diabetic retinopathy in type 2 diabetes Dyslipidemia and Diabetic Retinopathy in A Rural Population. Indian J Endocr Metab 2013; 17:S335-7.

34. Sasongko MB, Wong TY, Nguyen TT, Kawasaki R, Jenkins A, Shaw J, Wang JJ. Serum apolipoprotein AI and B are stronger biomarkers of diabetic retinopathy than traditional lipids. Diabetes Care 2011. 34(2):474-4

35. Agarwal RP, Meeta single, vyas SP, Sabir Hussain , Jain GC, Kochar DR. Prevalence of retinopathy and its relation with various risk factor in type $1 \mathrm{DM}-$ Hospital based study India. International journal of Diabetes In Developing Countries 2001; 21:184-190.

36. Sachdev N, Sahni A: Association of systemic risk factors with the severity of retinal hard exudates in a north Indian population with type 2 diabetes. Journal of Postgraduate Medicine, 2010;56(1):3-6.

\begin{tabular}{|c|l|}
\hline \multicolumn{2}{|c|}{ Access this Article in Online } \\
\hline Quick Response Code & Website: \\
\hline & Opw.ijcrims.com \\
\hline Oubject: \\
\hline
\end{tabular}

How to cite this article:

Swati Prajapati, Rashmi Kujur, U. S. Tiwari, K. P. Ranjan. (2017). Serum lipid levels in diabetes mellitus patients with and without diabetic retinopathy: A prospective study. Int. J. Curr. Res. Med. Sci. 3(8): 78-88.

DOI: http://dx.doi.org/10.22192/ijcrms.2017.03.08.013 